\section{REFERENCES}

1. Hartley J. Current findings from research on structured abstracts. J Med Libr Assoc. 2004 Jul;92(3):368-71.

2. Hartley J. Current findings from research on structured abstracts: an update [comment and opinion]. J Med Libr Assoc. 2014 Jul;102(3):146-8. DOI: http://dx.doi.org/10. 3163/1536-5050.102.3.002.

\section{AUTHOR'S AFFILIATION}

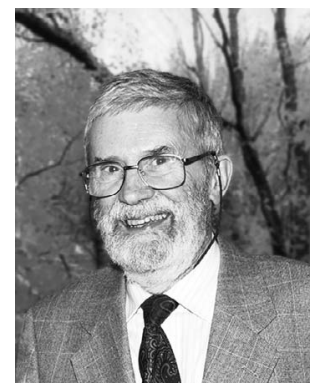

James Hartley, PhD, j.hartley@ keele.ac.uk, Emeritus Professor, School of Psychology, Keele University, Staffordshire, ST5 5BG, United Kingdom

\title{
Health sciences librarians off the radar
}

\author{
Sue Espe, BBA, MLIS, AHIP \\ See end of article for author's affiliation.
}

The library environment has undergone tremendous change through the years and with that change, the profession has had to adapt. These seemingly simple phrases written more than forty years ago continue to be as meaningful and applicable today as they were when written: "like everything else, libraries and library methods are changing at an increasing rate," and "'new things' have been and are happening in your field, and, indeed, some of these new trends seem to have come upon us quickly and, in some instances, have become drastic enough to threaten the very existence of the relatively small, professionally-supported medical library" [1]. Many health sciences libraries have adapted to accelerated technological advancements, fragmented collection acquisition models, altered space allocations, and modified user viewpoints. Particularly, health sciences libraries in hospitals have been profoundly impacted with library closures, bringing forth new thoughts related to value, adaptation, and change. In essence, this seemingly new trend of closures experienced today may not be so new after all, and the question that must be asked is, how has the health sciences hospital library continued to survive through the years?

One current unspoken, perhaps unconscious, survival tactic for many health sciences libraries involves working off the radar to avoid detection by administrators, who have the power to enforce decisions such as to forever close a library. In a business organization, there may be one ideal time to be off the radar and that occurs during the phase of bringing a new product to market. At that time, it is preferable to be off the radar of competitors, so they have little or no notice to attempt to copy the launched product, but once past the product introductory stage, it is best to be assertive by actively marketing the product. A prevailing business tactic for libraries to utilize is adherence to a marketing strategy that highlights remarkable operations in order to build strong business administrator and user relationships.

Having a strategic marketing plan is a practical tactic, helping to create a low-anxiety work environment that helps to assuage staff's debilitating fear of library closure or an underlying desire for the library to become invisible. Strategic marketing plans are a powerful tactic to lay the directional path to begin thinking with the mindset of a business organization. Marketing through a realistic analysis or strategic plan not only provides crucial promotion of exemplary library products and services, but also comforts staff who will know that steps are being considered to initiate long-term library survival. It is stated in psychological studies that "avoiding information is closely linked to feelings of anxiety and fear, as well as to other cognitive and emotional variables like perceptions of treatment efficacy, selfefficacy, and locus of control (the degree to which one's fate is governed externally versus controlled by one's self)" [2]. Being off the radar may provide comfort as a coping method against presumed 
disturbances or adversity, but the mistaken subtlety does not proactively lead the way for staff to attain optimal personal development or the library to achieve positive performance.

So, what are the first steps to market, and what are some novel marketing ideas? Start by writing a marketing plan that allows administrators and users to gain insight or learn about distinguishing library attributes. Deliberate attempts to actively pursue a strategic marketing plan allow a library to direct a vision to obtain growth and to avoid pitfalls. Determine and write broad goals, then list step-bystep objectives that state exactly how you will fulfill each objective. When you know what you want to accomplish, specifying detailed objectives of ways to implement goals will become much simpler. It is beneficial that "the capacity to create systematic plans to provide for the logistics of resources, support, training, and people is central to any program of change" [3].

As you write the marketing plan, consider the "4Ps" of basic marketing: product, price, promotion, and place. Investigate the external environment, confirm target users, and determine competitors. Specify qualities that truly define the product or service being offered with descriptive adjectives that someone could mentally identify and use words that bring imagery to mind and emotions to heart. Then, set the price, if applicable. If there is no associated cost, set a price anyway to establish a value-to-price comparison. Promoting to target users creates awareness, initiates interest, builds desire, and drives action. For each user group, determine a message to vocalize and a mechanism to deliver each message. For instance, perhaps you have a main goal to increase instructional sessions and an objective to provide advanced instruction about copyright to an identified user group of nurse educators. One message could be "Copyright Conundrum? What May or May Not Be Posted Online?" Once the messages have been written, determine the mechanism and routes for delivery.

It is also important to draw a timeline that ties the user to the message in conjunction with its route of delivery. Certain messages perform better at different times of the year, depending on the identified users. The timing of messages and frequency requires thoughtful consideration and perhaps adjustments through trial and error or learned experience. Regardless of the frequency, deliver messages on a continual, regular schedule, despite upturn or downturn situations. Businesses that continually market through tough economic times in order to remain on the forefront of consumers' minds will often be the first business that consumers remember when economic situations improve. Why? Because the consumers have been primed to do so through constant messaging.

Several areas are incorporated into marketing, and each has its unique opportunities for relaying your message. Decide if your message will be delivered through internal public relations, personal selling, sales promotion, multimedia advertising, direct mail, or online media. Your organization's public relations (PR) team may have routes to accomplished print and multimedia personnel who can assist with placing messages on television or radio either through free publicity or paid advertising. Specific library messages could plausibly be tagged to ride along with broader organizational messages, and oftentimes, nonprofit organizations benefit with free advertising spots. Advertising may also be placed in trade magazines, newsletters, or another print medium as well as on sides of buses, larger outdoor placards, or billboards, considered outdoor advertising. Most often, the advertising is paid, but in some instances, might be placed as goodwill for free.

Personal selling involves becoming visible and making the rounds through your organization's halls, visiting other department areas and staff in their personal offices or attending grand rounds. Create, memorize, and be ready to recite your elevator speech during impromptu meetings. Having a few short phrases memorized that describe your library products and services as well as carrying business cards or basket of novelties to hand out develops instant affinity and primes conversation. Typical sales promotion giveaways include pens, bookmarks, jump drives, stress balls, and tote bags that can easily be acquired through vendors of such products. Brainstorming creative sales promotion ideas with your staff for items to make or have made builds unity with a productive group endeavor in a fun, interactive environment.

Direct marketing allows your message to be delivered to a target audience based on defined, established criteria. It is a precisely targeted method to reach a particular audience, where the audience can be personified and visualized through its predetermined elucidated descriptors. One idea is to begin a direct mail campaign by sending out invitations or announcements through email or interoffice mail to a specific user group or 
department. For instance, a message about your library's online collection of textbooks could be directed to those nurses returning to school in a registered nurse $(\mathrm{RN})$ or bachelor of science in nursing degree (BSN) program. Use email as a direct mail mechanism, sending messages periodically at established times so that everyone begins to enthusiastically anticipate its receipt. Write teaser book reviews with unconventional, quirky subject lines to draw interest in opening your email, and close your message body with a prelude to a mysterious end to be read only in a following email. If you send a print mail piece, think about novel designs, such as a booklet or die-cut shape. In direct marketing, including an active pull mechanism, where recipients have to perform a task - such as send an email, place a sticker on a response card, or call to discover the complete message-builds intrigue, but more importantly, establishes commitment.

Produce a live skit or short advertisement and post a video of it on your intranet or library web pages. Integrate it with other promotional message mechanisms such as direct marketing, and mass email it within your organization. Think about current trends and pop culture to create novel spoofs. With a written marketing plan in place, knowing where to head and moving forward becomes a matter of action.

In this current environment of change-where many health sciences libraries are being downsized, restructured, or permanently closed-it is in your library's best interest to rise onto the radar and maintain visibility. It has been noted that "to manage changes effectively involves the ability to create a new synthesis of people, resources, ideas, opportunities, and demands" [3]. Many librarians mention avoidance as a key strategy in hopes of not being scrutinized. Too often, a librarian will be heard saying, "I will hold tight with the budget, staff and services that I have so as not to draw attention." It may be detrimental not to market, since it is very unlikely for a nondescript, covert library to receive positive appreciation or recognition. A proactive approach is much more beneficial. More than forty years ago, the astute William B. Condon, trustee of the Denver Medical Society, wrote, "frankly, a trustee wishes to be constantly, but gently, astutely, and diplomatically, nudged to keep his library functioning!" [1]. Librarians can benefit by following business practices to continually emphasize marketing promotion, and in essence, bring focus upon their libraries through strategic market planning.

\section{REFERENCES}

1. Condon WB. A medical society trustee looks at his library. Bull Med Libr Assoc. 1967 Jan;55(1):52-4.

2. Case DO, Andrews JE, Johnson JD, Allard SL. Avoiding versus seeking: the relationship of information seeking to avoidance, blunting, coping, dissonance, and related concepts. J Med Libr Assoc. 2005 Jul;93(3):353-62. 3. Barnes PC. Managing change. BMJ. 1995 Mar 4; 310(6979):590-2.

\section{AUTHOR'S AFFILIATION}

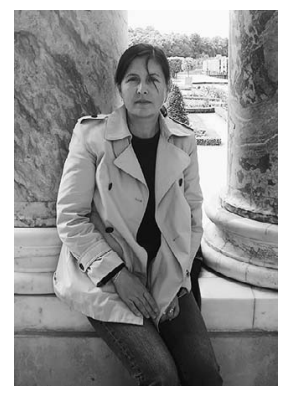

Sue Espe, BBA, MLIS, AHIP, suefue.espe@bannerhealth.com, Health Science Librarian, Banner Health-University Medical Center, 1111 East McDowell Road, Phoenix, AZ 85006

Received December 2015; accepted February 2016

\section{An elemental strategy}

\section{Nancy K. Roderer, MLS, FACMI, AHIP, FMLA}

See end of article for author's affiliation.

As medical libraries evolve and grow in the digital era, much has been much written about different aspects of the changes that have occurred. Less
DOI: http://dx.doi.org/10.3163/1536-5050.104.3.013

literature traces interrelated developments in a specific library over an extended period of time. To address this lack, the management team of the Welch 